\title{
The Association Between Platelet Mass Index and Mechanical Ventilation in Pediatric Surgery Cases
}

\begin{tabular}{|c|c|c|}
\hline Author (s) & \multicolumn{2}{|l|}{ (iD) Musa Silahlı } \\
\hline $\begin{array}{l}\text { Affiliation } \\
\text { (s) }\end{array}$ & \multicolumn{2}{|c|}{$\begin{array}{l}\text { Başkent University, Faculty of Medicine, Departments of Pediatrics, Division of Neonatology, Konya, } \\
\text { Turkey }\end{array}$} \\
\hline $\begin{array}{l}\text { Article } \\
\text { Information }\end{array}$ & $\begin{array}{l}\text { Article Type: Original Articles } \\
\text { Article Group: Pediatric Neonatology }\end{array}$ & $\begin{array}{l}\text { Received: } 04.06 .2021 \\
\text { Accepted: } 29.08 .2021 \\
\text { Available Online: } 29.08 .2021\end{array}$ \\
\hline
\end{tabular}

\section{Abstract}

Platelet mass index (PMI) is an indicator of platelet functionality. This study aimed to examine the relationship between $\mathrm{PMI}$ and mechanical ventilation need in infants less than 1 year of age who underwent gastrointestinal system surgery. We retrospectively reviewed the medical records of cases that underwent gastrointestinal surgery in the last 10 years (2010-2020) at Baskent University Konya Hospital. Demographic data, indications for surgery, age at surgery, preoperative blood tests, hospitalization times, discharge status, mechanical ventilation need and duration, sepsis, accompanying anomalies, recurrent surgery requirements were collected from patient records. The study group (n: 143) was divided into 2 groups as the need for mechanical ventilation (MV; n: 73) and the group that did not need mechanical ventilation (n-MV; $\mathrm{n}: 70$ ). Data were analyzed with SPSS version 25 . PMI was significantly lower in the MV group (1999 Vs 2798, p<.001). 65\% of the cases were newborns. Mean gestational age was $34.5 \pm 4$ weeks, and birth weight was $2100 \pm 820 \mathrm{~g}$. Most of the cases that need surgical intervention consist of small bowel atresia, esophageal atresia, surgeries due to necrotizing enterocolitis, and anal atresia. Ileus was present in $54 \%$ of the patients. The recurrent surgery requirement was $34 \%$. The frequency of accompanying cardiac anomalies was $30.6 \%$, and the rate of proven sepsis was $38.3 \%$. Preoperative $2163 \mathrm{PMI}$ value can discriminate not needing MV with $72 \%$ sensitivity and $69 \%$ specificity (AUC: .699, p<.001). When the basic characteristics of the groups were evaluated, $83 \%$ of the patients who underwent MV were in the newborn group. The birth weight, gestational age, hospital duration, oxygen exposure, culture-positive sepsis rates, total parenteral nutrition (TPN) rates, and duration were found to be significantly higher in patients who underwent MV. While there was no difference in the number of white blood cells in the preoperative blood analysis, the neutrophil-lymphocyte $(\mathrm{N}-\mathrm{L})$ ratio, platelet number, albumin values were significantly lower and CRP values were significantly higher in the MV group. There was no difference in the platelet-lymphocyte (PL) ratio. High PMI values can be used as a parameter to discriminate the need for mechanical ventilation.

Keywords: Platelet -mass index, pediatric surgery cases, mechanical ventilation, morbidities

Correspondence: Musa Silahlı, Baskent University, Faculty of Medicine, Departments of Pediatrics, Division of Neonatology, Konya, Turkey

E-mail: msilahli@gmail.com 


\section{Introduction}

The purpose of mechanical ventilation (MV) is to oxygenate the patient and remove carbon dioxide while trying to minimize damage to the lungs. Historically, positive pressure ventilation was the most widely used ventilation method in newborns. ${ }^{1}$ The management of infants receiving $\mathrm{MV}$ is largely dependent on personal preference. MV is a complex and highly specialized field in the infancy and newborn period made more complex by the availability of many different modes, techniques, and devices. This process becomes more complicated in preterm babies. ${ }^{2}$ Predicting which patients will need $M V$, extubation failure, and the need for long-term MV remain the subject of serious research.

Platelet mass index (PMI) is a marker of platelet activation and can be easily calculated by multiplying mean platelet volume (MPV) and platelet count. Its use of PMI in cases of bleeding has gained meaning with the understanding that larger platelets produce more reactive and more prothrombotic factors. ${ }^{3,4}$ It has been and continues to be the research subject of many studies that are thought to play a role in the physiopathology of inflammation, platelet functions, and mediators secreted in platelets.

This study was aimed to investigate the relationship between PMI and MV in pediatric surgical cases.

\section{Material and Method}

In this study, the medical records of infants under the age of 1 who underwent gastrointestinal system operations in pediatric surgery at Baskent University Konya Application and Research Center were examined retrospectively, from January 2010 to December 2020. This study was approved Baskent University Institutional Review Board and Ethics Committee (KA19/182, the $14^{\text {th }}$ of March, 2019). Patient data including age at operation, gestational age, mode of delivery, birth weight, gender, ileus status, number of reoperations, the hospital duration before surgery, the hospital duration after surgery, total hospital stay, invasive mechanical ventilation, and total oxygen exposure duration, discharge or death, preoperative full blood cell indices, and biochemical markers were obtained from medical records. In preoperative blood tests, PMI (mean platelet volume (MPV) * Platelet count $\left.\left(\mathrm{mm}^{3}\right) / 1000\right)$ values of all patients were calculated by the formula as described. Using receiver operating curve (ROC) curve analyzes, cut-off values were analyzed to discriminate whether the PMI variable needed MV or not. The best sensitivity and specificity values were determined. Descriptive statistics of scale variables were expressed as mean \pm standard deviation (SD) or median (range). Demographic and clinical continuous variables were compared using two independent Student's t-tests for normal distribution and the Mann-Whitney $U$ test for non-normally distributed values. Z scores of skewness, kurtosis, histograms, and Kolmogorov Smirnov statistics were used to understand whether the continuous variables are normally distributed. Categorical variables were compared using Fisher's exact test, Likelihood, or Chi-square test, as appropriate. ROC curve with area under the curve (AUC) was used to define sensitivity and specificity of PMI to discriminate not need for mechanical ventilation. Logistic regression analysis was used to estimate predictors of mechanical ventilation need. The significance level for all tests was determined as $p<0.05$.

Data were analyzed using the SPSS software package program version 25.

\section{Results}

Of the 143 patients included in the study, 73 were in the MV group and 70 were in the non-mechanical ventilation (n-MV) group. When the basic characteristics of the group were examined, $65 \%$ of them were newborns, the mean gestational age was $34.5 \pm 4$ weeks, and the mean birth weight was $2100 \pm 820 \mathrm{~g}$. Most of the cases that need surgical intervention consist of small bowel atresia, esophageal atresia, surgeries due to necrotizing enterocolitis, and anal atresia. lleus was present in $54 \%$ of the patients. The recurrent surgery requirement was $34 \%$. The frequency of accompanying cardiac anomalies was $30.6 \%$, and the rate of proven sepsis was $38.3 \%$. The majority of neonatal surgeries consisted of gastrointestinal malformations (intestinal atresia, esophageal atresia, anal atresia) and surgeries related to necrotizing enterocolitis. Distributions of the cases consisted of $21 \%$ (31) congenital small bowel malformations, $15 \%$ (22) esophageal atresia, 14\% (21) NEC, $13 \%$ (19) gastroesophageal reflux, gastrostomy, and hypertrophic pyloric stenosis surgery, 9\% (13) anogenital malformations, $7 \%$ (11) congenital megacolon, $4 \%$ (6) invagination, $2 \%$ (4) explorative laparotomy for free air in the abdomen, $2 \%$ (4) congenital diaphragmatic hernia and others $(13 \%)$ including malrotation, colon perforation, britt ileus and constituted the closure of the colostomy. Considering the group statistics, while birth weight (2138 $\pm 868 \mathrm{gr}, \mathrm{p}: 0.001)$, week of birth $(33.7 \pm 4$, p: $0.001)$, age at the time of diagnosis $(7,1-260, p<0.001)$ were significantly lower in the MV group, duration of oxygen use $(p<0.001)$, length of hospital stay $(p<0.001)$ in both preoperative and postoperative, total parenteral nutrition (TPN) duration $(p<0.001)$ and percentage of TPN recipients $(p<0.001)$, rates of sepsis $(p<0.001)$ and surgery under 1 month $(p<0.001)$ were found to be significantly higher (Table 1). There was no difference between the groups in terms of gender, need for recurrent surgery, and concomitant complex heart diseases. When the preoperative blood indices were examined, no difference was found between the groups in terms of white blood cell counts and Platelet lymphocyte ratio (PLR), while PMI $(p<0.001)$, albumin $(p<0.001)$, and platelet values $(p<0.001)$ were found to be significantly lower in the MV group (Table 2). In addition, preoperative hemoglobin $(p=0.037)$, neutrophil-lymphocyte ratio $(\mathrm{NLR})(p<0.001)$, and $C$ - reactive protein $(C R P)$ values $(p=0.008)$ were significantly higher in the MV group (Table 2). In the performed ROC analysis to discriminate 
PMI needing mechanical ventilation, a PMI value of 2163 can discriminate not needing MV with $72 \%$ sensitivity and $69 \%$ specificity (AUC: $0.699, \mathrm{p}<0.001$ ), although PMI has a mild and moderate discrimination (Figure 1). A regression model which was created scientific knowledge and parameters that could be the risk factors in pairwise comparisons, has been performed to ascertain the effects of the gestational week, proven sepsis, recurrent surgery needs, and PMI on the probability that participants have mechanical ventilation. The logistic regression model was statistically significant, $x^{2}=16, p=0.003$. To assess the model fit, Hosmer-Lemeshow statistics was good $(p=0.449)$ The model explained 29\% (Naegelkerke R2) of the variance in the mechanical ventilation group, and correctly classified $70 \%$ of the cases. In the logistic regression model of independent risk factors predicting the need for MV, it is understood that the most important risk factor was sepsis (p: 0.020, OR: $4.86,95 \% \mathrm{Cl}$ : [1.277-18.53]) (Table 3).

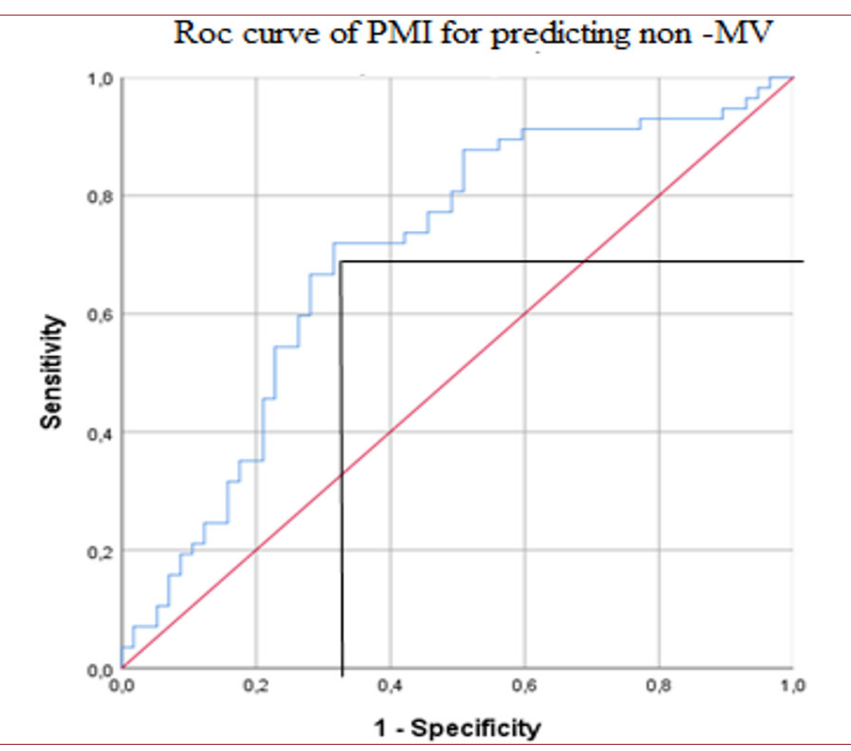

Figure 1. ROC curve showing diagnostic performance of $\mathrm{PMI}$ in predicting that will not require mechanical ventilation.

\begin{tabular}{|c|c|c|c|}
\hline & $M V(n=73)$ & $n-M V(n=70)$ & P-value \\
\hline Birth weight gr; Meant $\pm S D$ & $2138 \pm 868$ & $2890 \pm 780$ & 0.001 \\
\hline Gestational age, Meant $\pm S D$ & $33.7 \pm 4$ & $36.5 \pm 2$ & 0.001 \\
\hline Gender, Male; n (\%) & $42(60)$ & $43(59)$ & 0.894 \\
\hline Age at diagnosis (day); median (min-max) & $7(1-210)$ & $37.5(1-360)$ & $<.001$ \\
\hline The need for recurrent surgery,median, (min-max) & $0(0-3)$ & $0(0-4)$ & 0.728 \\
\hline Hospital duration (day); median (min-max) & $35(1-301)$ & $8.5(1-120)$ & $<.001$ \\
\hline Hospital duration before surgery; day median (min-max) & $3(0-64)$ & $1(0-12)$ & $<.001$ \\
\hline Hospital duration after surgery; day median (min-max) & $25(1-288)$ & $7(1-116)$ & $<.001$ \\
\hline The time of Oxygen exposure; day; median (min-max) & $19(1-301)$ & $0(0-23)$ & $<.001$ \\
\hline TPN rate; $\mathrm{n}(\%)$ & $65(91.5)$ & $20(28.6)$ & $<.001$ \\
\hline TPN duration; median (min-max) & $16(0-232)$ & $0(0-87)$ & $<.001$ \\
\hline Proven sepsis; $\mathrm{n}(\%)$ & $46(65)$ & $8(11)$ & $<.001$ \\
\hline Concomittant hearth desesase; n (\%) & $35(49.3)$ & $9(12.9)$ & $<.001$ \\
\hline Concomittant complex hearth desesase; $\mathrm{n}(\%)$ & $6(8.5)$ & $1(1.4)$ & 0.116 \\
\hline Surgery less than 1 month old age; $n(\%)$ & $61(83.6)$ & $32(45.7)$ & $<.001$ \\
\hline
\end{tabular}

\section{Table 2.}

Preoperative whole blood cell counts, calculated indices and biochemical values of the groups

\begin{tabular}{|c|c|c|c|}
\hline & $M V(n=73)$ & $n-M V(n=70)$ & $P$-value \\
\hline Leucocyte count $/ \mathrm{mm}^{3}$ Mean \pm SD & $13232 \pm 7250$ & $12085 \pm 5420$ & 0.309 \\
\hline $\mathrm{Hgb}(\mathrm{gr} / \mathrm{dl}) \quad$ Mean $\pm \mathrm{SD}$ & $14.1 \pm 3.9$ & $12.8 \pm 3$ & 0.037 \\
\hline Platelet count $/ \mathrm{mm}^{3}$ Mean \pm SD & $222845 \pm 129683$ & $374574 \pm 173103$ & $<.001$ \\
\hline N/L ratio; median (min-max) & $1.37(0.06-52.7)$ & $0.73(0.1-4.88)$ & $<.001$ \\
\hline P/L ratio; median (min-max) & $39.2(8.38-293)$ & $64.9(2.64-2029)$ & 0.58 \\
\hline PMI ; Mean \pm SD & $1999 \pm 1131$ & $2798 \pm 1301$ & $<.001$ \\
\hline Albumin (gr/dl); Mean $\pm S D$ & $2.88 \pm 0.5$ & $3.47 \pm 0.6$ & $<.001$ \\
\hline $\operatorname{Crp}(\mathrm{mg} / \mathrm{L}) ;$ median (min-max) & $13.8(0.1-339)$ & $1.2(0.1-238)$ & 0.008 \\
\hline
\end{tabular}

Abbreviations: MV: Mechanical ventilation; n-MV: Non mechanically ventilated; TPN: Total parenteral nutrition; SD: Standart deviation; PMI: Platelet mass index; N/L ratio: Neutrophil to lymphocyte ratio, P/L ratio: Platelet to Lymphocyte ratio; CRP: C-reactive protein

\begin{tabular}{lcccc} 
& B & P value & Exp (B) & Confidence Interval (95\%) \\
\hline Gestational age & -0.144 & .160 & .886 & $0.709-1.058$ \\
The need for recurent surgery & -0.823 & .188 & 0.439 & $0.129-1.497$ \\
Cultur positive proven sepis & 1.582 & 0.020 & 4.864 & $1.277-18.530$ \\
PMI** & 0 & 0.139 & 1 & $0.999-1.000$
\end{tabular}




\section{Discussion}

MV applications are frequently used in intensive care units both preoperatively and postoperatively, especially in critical patients and neonatal-infant surgery. Invasive mechanical ventilation is required in $35 \%-64 \%$ of pediatric intensive care units all over the world. ${ }^{7,8}$ It is known that increased mechanical ventilation time is associated with increased mortality and morbidity. ${ }^{9}$ It is very important to investigate whether mechanical ventilation is required and risk factors. As a result of this study, it was concluded that it can be discriminated whether MV will be required with preoperative PMI values.

Okur et al.'s study on the use of PMI as a predictor of neonatal morbidity and mortality in preterm infants, the authors reported that cases with necrotizing enterocolitis (NEC), intracranial hemorrhage (IVH), bronchopulmonary dysplasia (BPD), retinopathy of prematurity (ROP), and sepsis were included in the study, and found that they had significantly lower PMI values than those who did not. ${ }^{5}$ They explained these results with inflammation. In our study, we found a significantly lower PMI in patients who underwent $M V$, patients who required TPN, and patients who underwent surgery in the newborn, but we did not find a significant difference in the sepsis group. Okur et al. obtained PMI results on two different days from whole blood data taken on day 1 and between 3-7 days. This may have affected the results. The reason for the lack of difference in sepsis in our study was interpreted as the fact that culture-positive sepsis cases consisted of data obtained at any time after surgery, and preoperative PMI values could perhaps shed light on early postoperative periods. In the same study, they found a significant relationship between PMI values calculated from blood taken between 3-7 days and MV, but they did not find a difference between PMI values on the first day. The reason for this seems to be that sepsis and infections developing in the postoperative period affect $\mathrm{PMI}$ values.

In the study of Ilhan et al. in which PMI and respiratory morbidities were compared in infants with transient neonatal tachypnea, they found that infants with lower $\mathrm{PMI}$ values had longer tachypnea duration, more oxygen need, and more mechanical ventilation need, similar to our study. ${ }^{6}$

Recent studies have shown that the lungs have important roles in platelet function and production. Megakaryocytes produced in the bone marrow come to the lungs through the bloodstream. It differentiates from megakaryocytes to platelets by various signaling systems. Approximately $50 \%$ of total platelet production occurs in this way..$^{10} \mathrm{It}$ has been shown in animal experiments that mediators such as platelet glutathione redox cycle antioxidants released from platelets in the lung after ischemia-reperfusion injury or oxidant stress have effects on endothelial permeability and pulmonary edema are evident in experimental animals with thrombocytopenia. ${ }^{11-13}$ In addition, studies have shown the functions of platelets in lung defense mechanisms, inflammation, and remodeling events in healthy lungs. ${ }^{14}$

\section{Conclusion}

As a result; we think PMI values, which are accepted as an indicator of platelet functionality, can be used to discriminate the need for mechanical ventilation, especially since the platelets are in a very important and close relationship with the lungs.

Acknowledgements: This study was presented as an oral presentation in the $7^{\text {th }}$ Erciyes Pediatric Winter Academy Congress. I would like to thank all health care providers who contributed to the diagnosis, treatment, care, and follow-up of patients.

Author Contributions: All of the authors declare that they have all participated in the design, execution, and analysis of the paper and that they have approved the final version

Conflict of Interest: All the authors declare that they have not received any financial support or other benefits from commercial sources for the work described in this paper. They also declare that they have no other financial interests that could create a potential conflict of interest or the appearance of a conflict of interest with about this work.

Ethics Committee Approval: This study was approved Baskent University Institutional Review Board and Ethics Committee (KA19/182, the $14^{\text {th }}$ of March, 2019).

Financial Disclosure: The authors declared that this study has received no financial support.

Informed Consent: Because the study was designed retrospectively, no written informed consent form was obtained from patients.

\section{References}

1. Swyer PR, Reiman RC, Wright JJ. Ventilation and ventilatory mechanics in the newborn: methods and results in 15 resting infants. J Pediatr. 1960;56:612-622. [CrossRef]

2. Sant'Anna GM, Keszler M. Weaning infants from mechanical ventilation. Clin Perinatol. 2012;39:543-562. [CrossRef]

3. Kamath S, Blann AD, Lip GY. Platelet activation: assessment and quantification. Eur Heart J. 2001;22:1561-1571. [CrossRef]

4. Martin JF, Trowbridge EA, Salmon G, Plumb J. The biological significance of platelet volume: its relationship to bleeding time, platelet thromboxane B2 production and megakaryocyte nuclear DNA concentration. Thromb Res. 1983;32:443-460. [CrossRef]

5. Okur N, Buyuktiryaki M, Uras N, et al. Platelet mass index in very preterm infants: can it be used as a parameter for neonatal morbidities?. J Matern Fetal Neonatal Med. 2016;29:3218-3222. [CrossRef]

6. Ilhan O, Bor M. Platelet mass index and prediction of severity of transient tachypnea of the newborn. Pediatr Int. 2019;61:697-705. [CrossRef]

7. Farias JA, Frutos F, Esteban A, et al. What is the daily practice of mechanical ventilation in pediatric intensive care units? A multicenter study. Intensive Care Med. 2004;30:918-925. [CrossRef]

8. Randolph AG, Meert KL, O'Neil ME, et al. The feasibility of conducting clinical trials in infants and children with acute respiratory failure. Am J Respir Crit Care Med. 2003;167:13341340. [CrossRef]

9. Principi T, Fraser DD, Morrison GC, et al. Complications of mechanical ventilation in the pediatric population. Pediatr Pulmonol. 2011;46:452-457. [CrossRef]

10. Lefrançais E, Ortiz-Muñoz G, Caudrillier A, et al. The lung is a site of platelet biogenesis and a reservoir for hematopoietic progenitors. Nature. 2017;544:105-109. [CrossRef] 
11. Heffner JE, Cook JA, Halushka PV. Human platelets modulate edema formation in isolated rabbit lungs. J Clin Invest. 1989;84:757-764. [CrossRef]

12. Zamora CA, Baron D, Heffner JE. Washed human platelets prevent ischemia-reperfusion edema in isolated rabbit lungs. $J$ Appl Physiol (1985). 1991;70:1075-1084. [CrossRef]
13. Lo SK, Burhop KE, Kaplan JE, Malik AB. Role of platelets in maintenance of pulmonary vascular permeability to protein. Am J Physiol. 1988;254:H763-H771. [CrossRef]

14. Weyrich AS, Zimmerman GA. Platelets in lung biology. Annu Rev Physiol. 2013;75:569-591. [CrossRef] 